\title{
Children and Added Sugar: The Case for Restriction
}

\section{THEODORE BACH}

ABSTRACT It is increasingly clear that children's excessive consumption of products high in added (or extrinsic) sugar causes obesity and obesity-related health problems like type 2 diabetes, cardiovascular disease, and metabolic syndrome. Less clear is how best to address this problem through public health policy. In contrast to policies that might conflict with adult's right to self-determination - for example sugar taxes and soda bans - this article proposes that children's access to products high in added sugars should be restricted in the same way that children's access to tobacco products is restricted. The article first considers how the recommended policy will protect a child's right to an open future while not violating parental rights. The article then explores how the implementation of the recommended policy can help transform the social meaning of sugar and thereby curb the parental supply of added sugar to children - a central cause of obesity. The article also addresses several potential objections.

\section{Introduction}

Public health experts agree that obesity, defined as a percentage of body mass index, ${ }^{1}$ is pandemic globally and epidemic in the United States. Focusing on just the US: at least one in three adults is obese, at least one in six children is obese, and at least one in eight preschoolers is obese. ${ }^{2}$ The chances of an overweight or obese preschooler becoming an obese adult are five times greater than that of a normal weight child. ${ }^{3}$ Obesity-related diseases - which include type 2 diabetes, cardiovascular disease, cancer, sleep apnea, and metabolic syndrome - can have a strong negative impact on individual wellbeing. Moreover, the annual amount of medical expenses attributable to obesity is approximately 150 billion dollars. ${ }^{4}$

While there are many causes for the rise of obesity and obesity-related health problems, it is increasingly clear that adult's and children's excessive consumption of added (or 'extrinsic') sugars is a central causal factor. Unlike sugars found in fruit and milk, added sugars occur non-naturally - they are manufactured and added during food processing, they are added at the kitchen table in the form of manufactured syrups or sweeteners, and they are consumed separately. Items high in added sugar include syrups, sodas, sweetened fruit drinks, energy drinks, candy, and grain-based desserts like brownies and cake.

The body processes calories from added sugar in the same way that it processes calories from naturally occurring sugars. However, added sugars, because they are not generally packaged in nutrient dense foods and beverages, have a distinct causal impact on weight gain and the onset of obesity. There is now strong empirical support for the causal link between the over-consumption of items high in added sugars and obesity. For example, recent systematic reviews and meta-surveys (that evaluate both prospective 
cohort studies and randomised controlled trials) on the relationship between sugarsweetened beverage intake and weight gain report a significant positive relationship. ${ }^{5}$ In response to these and similar data, and in order to reduce significantly the rates of obesity in the US, the American Heart Association, the US Department of Agriculture, and the US Dietary Guidelines Review Committee have each recommended sharp reductions in people's consumption of added sugars.

The successful implementation of these recommendations will require a variety of public policy initiatives that include education and industry regulation (i.e. consumer protection). Nonetheless, a number of public health experts and public officials contend that such measures are insufficient to address the obesity problem and that specifically coercive paternalistic policies - policies that either penalise or narrow the choices of rational adults - are also required to reduce significantly obesity rates and obesityrelated health problems. For example, in 2012 the New York City Board of Health passed Health Code $\$ 81.53$ that would make it illegal for certain types of vendors to sell to anyone 'sugary drinks' over sixteen ounces (the health code was later invalidated by the New York County Supreme Court). More recently, in November 2014, the city of Berkeley, California passed a measure that would impose a one cent per ounce tax on sugar-sweetened beverages.

This article will grant that more than improved education and consumer protection is needed to curb the obesity epidemic. However, rather than advance coercive paternalistic policies this article makes the case for an alternative. The article proposes that specifically children's access to products very high in added sugars should be restricted in the same (or similar) way that children's access to tobacco and alcohol products is restricted. I argue that this proposal would be effective at lowering sugar consumption and obesity rates while at the same time protecting adult decision-making. In Section 3 I argue that the recommended policy is needed in order to protect children's right to an open future. In that section I also consider the policy in relation to parental rights (3.1) and children's right to sources of caloric energy (3.2). In Section 4 I argue that implementing the recommended policy will promote the public good because it will help reduce the incidence of obesity-related health conditions. A central premise of that argument is the claim that the recommended policy is well positioned to transform the social meaning of sugar and thereby limit the parental supply of sugar to children. Section 5 concludes and also suggests a general schema for the legal restriction of children's activities.

\section{Restricting the Sale of Items High in Added Sugar to Minors}

The recommended policy would make it illegal for any vendor to sell any product with a sufficiently high percentage of added sugar to minors. Below are four points that further develop this policy.

First, it is important to note the generality of the policy. As argued by Justice Tingling, New York City Health Code $\$ 81.53$ was problematically arbitrary - it applied 'to some but not all food establishments in the city, [and] it excludes other beverages that have significantly higher concentrations of sugar sweeteners and/or calories on suspect grounds . . ${ }^{6}$ In contrast, the recommended policy does not provide exceptions for any type of vendor or product type. This is analogous to restrictions on the sale of tobacco that do not provide exceptions for any type of vendor or type of tobacco. 
Second, for the present I leave open the exact percentage of an item's total caloric content derived from added sugars that will place it in the minor-restricted class. Perhaps careful deliberation on this point will lead to the restriction of only sugary beverages. On the other hand, such deliberations might cordon off a much larger class of food and beverage products. While I suggest that the target added sugar caloric percentage should be at least low enough to include items like Dr Pepper, 3 Musketeers Bars, and Froot Loops, I leave aside this debate here. Instead, I will focus on more general arguments that concern the moral status of public policies that legally restrict children's purchasing power.

Third, for the present I leave open the precise definition of 'minor' while noting the importance of the following considerations. On the one hand, the age-related prevalence of driver's licenses and identification cards provide pragmatic reasons for establishing ' 18 ' as the cut-off. On the other hand, logistical and legal models are now available for the regulation of minor's purchasing activity when the relevant age demarcation is established under the age of 18. For example, many US states - Georgia, New Hampshire, and North Carolina to name a few - now ban the use of indoor tanning beds for children under the age of 14 (unless medically necessary). ${ }^{7}$ Moreover, many US states for example New York and Virginia - make available non-driver photo identification cards to children of any age. Considerations based on the wellbeing of the developing child may also favour this earlier cut-off age. For instance, issuing identification cards to younger teenagers could open up a unique and developmentally valuable domain of decision-making. Adjusting to this responsibility — for example, deciding whether to use one's legal status to buy items high in added sugar for younger children - could provide valuable training for handling similar but more dangerous future responsibilities — for example, deciding whether to buy tobacco and alcohol products for younger teenagers. More generally, teenagers would learn about the complex moral, social, and legal dynamics of buying items high in added sugar before they face these similar dynamics with respect to tobacco and alcohol products. Of course, the developmental value of such autonomy training must be weighed against the potential harms (described in more detail below) that can result from granting younger teenagers the legal freedom to purchase items excessively high in added sugar.

Fourth, and by deliberate omission, the policy allows that parents and legal guardians (hereafter 'parents') can legally purchase sugar products from the restricted class for their children. Thus, children can still enjoy holiday cookies and birthday cakes - but at their parent's discretion. Related, the policy does not make it illegal for minors to consume, in any context, the restricted class of items. It only makes it illegal for vendors to sell to minors the restricted class of items. If this combination of legal restrictions and freedoms appears unintuitive or conflicting, one should note that this is the same combination of legal freedoms and restrictions that often applies to parents and children with respect to tobacco and alcohol products. For example, if you are thirteen and you live in Massachusetts, it is illegal for you to be sold tobacco products. However, it is not illegal for your parents to provide you with tobacco products or for you to consume tobacco products. I revisit this balance of parental freedoms and child restrictions in Section 3.1.

For the remainder of the article I advance several mutually supporting arguments in favour of the recommended policy. I contend that, at a minimum, these arguments together shift the burden of proof onto those who would defend the legal right of vendors to sell to minors items sufficiently high in added sugar. But I also contend that the 
arguments show more - they show that the recommended policy is legally and morally preferable to current policies (or the lack thereof) for the regulation of children's access to items high in added sugar.

\section{Added Sugar and Children's Right to an Open Future}

Many activities are legal for adults but not for children, and many of these legal differences are justified in reference to differences in moral rights. These moral differences, in turn, are grounded in the dependency and vulnerability of the child, on the one hand, and the more fully formed personhood or autonomy (understood as the capacity to self-govern) of the adult on the other. For example, in order to justify his or her legal right to enlist in a military combat unit, we can reference a twenty-seven-year-old's autonomy and derivative moral right to self-determination. And we can reference a ten-year-old's vulnerability, moral right to protection, and underdeveloped autonomy in order to justify the legal restriction of his or her joining the same military combat unit.

Yet the above (brief) remarks leave out an important class of children's rights. A child's future personhood and future right to self-determination are also relevant to the question of whether the child is subject to special legal restriction or protection. Feinberg notes that each child is potentially an adult and ' . . it is that adult who is the person whose autonomy must be protected now (in advance)' ${ }^{8}$ Feinberg uses the notion of 'anticipatory autonomy rights', or more generally the 'right to an open future', to capture children's (and their future selves) right to this form of protection. This right takes precedent for children but not for most adults:

When a mature adult has a conflict between getting what he wants now and having his options left open in the future, we are bound by our respect for his autonomy not to force his present choice in order to protect his future 'liberty'. His present autonomy takes precedence over his probable future good, and he may use it as he will, even at the expense of the future self he will one day become. Children are different. Respect for the child's future autonomy, as an adult, often requires preventing his free choice now. Thus the future self does not have as much moral weight in our treatment of adults as it does children. ${ }^{9}$

Consider the decision to acquire a bold and permanent face tattoo. A mature adult's right to self-determination grants that adult the right to acquire such a tattoo even if doing so irreversibly narrows future possibilities. On the other hand, we would not grant a five-year-old the right to acquire on his or her own this same tattoo. Bold and permanent face tattoos can significantly constrain one's future social and professional opportunities, and given the child's still underdeveloped capacity to self-govern, the child's right to self-determination does not take precedent here over the child's right to an open future. Only the adult who that child will become should have the right to select this (future-restricting) appearance.

In order to motivate the application of this category of rights to children's purchasing access to added sugars, it is instructive to first consider children's purchasing access to e-cigarettes. Whereas traditional cigarettes use tobacco and smoke to deliver nicotine, e-cigarettes use batteries to heat liquid nicotine which is then inhaled as a vapor. Should children have the legal right to purchase e-cigarettes? As of March 2015, there remain 
nine US states that do not impose age restrictions on the sale of e-cigarettes (although this is likely to change as a result of upcoming rulings from the US Food and Drug Administration). Not much is currently known about the health effects of e-smoking, and there is currently little or no empirical evidence that e-smoking causes cancer. ${ }^{10} \mathrm{With}$ this empirical point in doubt, it is at present difficult to argue on the basis of the harmful health effects of e-smoking that children ought not to have legal access to e-cigarettes. However, a more rationally persuasive argument for withholding children's legal right to purchase e-cigarettes - one that appeals to children's right to an open future - is available. It is well known that nicotine is highly addictive and that an adult life governed by nicotine addiction (and regardless of whether one transitions to traditional smoking) places a variety of important restrictions on one's behavior, choices, and lifestyle. Given children's underdeveloped capacity for informed self-governance, their moral right to an open future should thus deny them the legal opportunity to purchase e-cigarettes. My stronger claim is that, given the current lack of empirical evidence related to the health effects of e-smoking, the only effective rights-based argument for restricting the sale of e-cigarettes to children requires appeal to children's right to an open future. This stronger claim indicates that this category of rights has both an important and intuitive application to the restriction of children's purchasing power.

I now turn to children's legal access to items high in added sugar. I claim that current regulatory policies that make it legal for vendors to sell products with a sufficiently high percentage of added sugar to minors constitute a violation of children's right to an open future. My contrasting and recommended policy functions to protect that right.

As discussed in section (1), it is increasingly clear that children's over-consumption of added sugars is causally linked to childhood obesity. Unfortunately, a child's condition of being overweight or obese is much less likely to be reversed than one might hope. Overweight and obese children are significantly more likely to become obese adolescents, and most obese adolescents become obese adults. A recent longitudinal study found that overweight 5 -year-olds were four times more likely than normal weight children to become obese as 14 -year-olds. ${ }^{11}$ Another longitudinal study determined that 'only a small proportion of adolescents (ages 13-20 y) moved out of the obese category as they became adults (19-26 y)'. ${ }^{12}$ Importantly, even if a child, adolescent, or adult successfully exits the obese category, they are still more likely to suffer obesity-related health problems than had they never been overweight or obese at a younger age. For example, a recent review of several longitudinal cohort studies revealed that childhood obesity can increase morbidity and mortality rates for adults independent of the body mass index of these adults. ${ }^{13}$ Moreover, a significant number of researchers now argue on empirical grounds that sugar is addictive and that many cases of obesity are explicable on the model of drug addiction. ${ }^{14}$

The above considerations indicate respects in which children's dietary behavior can set them on a trajectory that is not easily reversed and that can have profound and negative consequences for their future wellbeing. These negative consequences consist primarily in obesity-related health conditions - for example type 2 diabetes and metabolic syndrome - that, in addition to causing pain, suffering, or shortened lifespan, can restrict an individual's social and economic opportunities. ${ }^{15}$ Now, if children had a sufficient capacity to self-govern in this domain, then one could reasonably argue that children's right to self-determination should take precedent over any harm (even if long-term and irreversible) that might follow from their decision-making. But there are several reasons 
for rejecting the antecedent of the above conditional. One set of reasons is epistemic: the scientific community is just now learning about many of the harmful effects of added sugar consumption and obesity, so one cannot reasonably expect that young children will have sufficient grasp of these (often complicated) harmful effects. There are also several non-epistemic factors that impede children's ability to reason carefully about the relationship between sugar consumption and future wellbeing. Consider that humans have a biological preference for sweet tastes and that this preference is significantly higher in children. ${ }^{16}$ Indeed: food scientists - well-funded by companies like Nestlé and General Mills - investigate how best to exploit this innate preference, and corporate funded scientific trials have determined children's 'bliss point' - the maximum level of sweetness that kids will crave - for various classes of products like pudding and soda. Then, with their marketing arm, these same companies use carefully targeted advertising in order to manipulate children's psychological mechanisms for decision making. ${ }^{17}$ Given children's biology and their limited ability for long-term practical reasoning, they stand little chance against this carefully coordinated and heavily subsidised effort.

To summarise: by not allowing children to engage legally in transactions that can significantly narrow the possibilities and choices for the adults who such children will become, the recommended policy protects children's right to an open future.

\subsection{Parental Rights and Added Sugar}

Given the various harms - both current and future - associated with children's sugar consumption, one might wonder why the recommended policy does not also restrict the right of parents to provide children with items sufficiently high in added sugar. In this section I provide reasons for permitting but regulating the parental supply of items high in added sugar. I take as my model the methods that many US states employ for permitting but regulating the parental supply of alcohol and tobacco products.

Consider a family in which the parents allow their children to have a small glass of wine during Sunday dinners. The parents believe that this practice promotes family bonding, and they also believe that the practice will make it less likely that their children will become binge drinkers while in college. Very rarely - maybe twice a year - the family also shares a hookah (a smoking device of Middle Eastern origin that can be passed between people). The parents believe that this practice is an important cultural tradition and that it promotes family bonding. Outside of these rituals, the parents closely monitor and forbid their children to consume alcohol and tobacco products.

Whether or not we would recommend to parents that they establish such rituals, I submit that parents should have the legal right to manage their families in this way. In such cases, the actual or potential harms caused by the children's consumption of the minor-restricted items do not appear to outweigh the harm that would result from restricting the parent's freedom to manage their family in this way. For the same reason, I contend that parents ought to have the legal right to incorporate items high in added sugar into family activities. The conditions and rituals in which they might do so birthdays, Halloween, religious holidays, and so on - are quite familiar.

Of course, not every family is as responsible as the one described above. Some parents facilitate and subsidise their children's chain-smoking and binge drinking. Fortunately, state policies dictate that social workers intervene in such cases. One justification for such intervention is that, in these cases, the harm caused to the child outweighs the harm 
caused by restricting the parental freedom. Similarly, and in the context of the recommended policy for restricting children's purchasing power, I suggest stronger state policies that require social workers to intervene in cases in which the current or future harm caused by a child's excessive consumption of parent-supplied added sugar outweighs any harm that would come from restricting the parental freedom to supply such items. As is the case for tobacco and alcohol related intervention, it would be essential to assess carefully the degree and source of the harm to child. ${ }^{18}$

There is a second reason for providing parents the legal right to supply children with items high in added sugar. As I will discuss in Section 4, it is not unreasonable to think that the proposed policy, if implemented and adequately enforced, will over time significantly change the 'social meaning' of sugar. Much less clear is whether a policy that required the complete prohibition of children's consumption of items high in added sugar could achieve a similar effect. To illustrate this point, it may be helpful to recall the two versions of Peter Singer's 'principle of preventing bad occurrences' as set out in his landmark 1972 article 'Famine, Affluence, and Morality'. ${ }^{19}$ While Singer regarded the 'strong' version of this principle — which would require people to sacrifice their material possessions until they reached the point of 'marginal utility' - as correct, he advocated for a 'moderate' version that required less material sacrifice. Singer recognised that, given people's current conceptual scheme for giving and material possession, the strong principle would be unlikely to achieve much traction. On the other hand, if people were to adopt the moderate principle, then this would mark a conceptual shift that could eventually make the stronger principle a live option. Similarly, even if one were convinced of the moral justification for the complete prohibition of children's consumption of items sufficiently high in added sugar, it would appear that the current social meaning of sugar in the US is such that the implementation of this prohibition would be, at least at present, a practical impossibility. However, an effective means of bringing about the conceptual change required to make this prohibition (or the interventionist measures discussed above) a live option is to implement the recommended policy for restricting the sale of sugary items to minors. I will further explore the projected impact of the recommended policy on the social meaning of sugar in Section 4.

A final and related argument for permitting the parental supply of added sugar is that it could mitigate the potential for a 'forbidden fruit' or 'boomerang' effect. This effect would occur if restricting children's access to items high in added sugar caused these items to become more attractive and, as a result, promoted increased rather than decreased consumption of these items. However, because the recommended policy allows children to consume items high in added sugar in the context of parental supervision, it is less likely to cause such a boomerang effect than if children were given no legal access whatsoever to items high in added sugar. Analogously, and as reported in several empirical studies, ${ }^{20}$ the responsible parental supply of alcohol during meals in various Mediterranean countries is associated with lower rates of future binge drinking and alcohol abuse than is alcohol abstinence.

\subsection{Two Rights-Based Objections to the Restricted Sale of Sugary Items to Minors}

One possible objection to my rights-based argument for restricting the sale of sugary items to minors begins with the accurate claims that added sugar is a source of calories 
and that calories are required for human health and survival. The objection then infers from these claims that a policy that legally prohibits children's access to added sugar a source of essential calories - violates children's basic rights.

A thought-experiment will show why the argument's conclusion does not follow from its premises. Suppose that a tobacco company develops a new type of cigarette. This new cigarette is just like traditional cigarettes except that smoking this cigarette will cause caloric energy to be released in one's body (we can stipulate that this is an effect of the company's new recipe for nicotine delivery). The savvy company markets this new brand of cigarette as Energy Cigs and sends lobbyists to Capitol Hill in order to secure the legal right to sell Energy Cigs to consumers under the age of 18.

In this scenario, would it be appropriate to legalise the sale of Energy Cigs to minors? Should we be persuaded by the Energy Cigs lobbyist who pleads to legislators that 'Energy Cigs are an excellent source of calories — indeed, calories required for human survival! - and to ban the sale of Energy Cigs to children is to violate children's right to life!'? I assume that the answer to both these questions is 'no'. The thought experiment reveals that an item's inclusion of a life-essential substance is not sufficient to justify the legal sale of that item to minors. To justify such a sale one would additionally have to show that the target item is an indispensable source of the life-essential substance. For example, if Energy Cigs were the only viable source of calories for children, then our intuition about the case changes. Similarly, if products high in added sugar were the only viable source of calories for children, then the recommended policy should not be implemented. But it is not the case that products high in added sugar are the only viable source of calories for children. While it is problematic that certain locations are underserved by vendors offering healthy foods and beverages, it is simply incorrect to claim that items like milk, bananas, potatoes, and beans, while not always conveniently located, are not available to children or their parents. (Note that implementing and enforcing the recommended policy could provide an incentive for vendors to supply such healthier items.)

A related objection claims that the policy's restriction of rights is inconsistent because it allows children legal access to calories in one form - in milk and fruits, for example - but not in another form - in candy and soda, for example. This objection fails because it misses the importance and causal relevance of relational and historical properties. When considering whether a substance poses a danger to consumers or whether consumers are legally entitled to that substance, it is important to investigate the relational and historical properties in addition to the intrinsic properties of that substance. I assume that the relation of ethyl alcohol to other substances in a bottle of whisky is one that justifies restricting the sale of ethyl alcohol qua whisky to minors. On the other hand, I assume that the relation of ethyl alcohol to other substances in a bottle of vanilla extract, in a bottle of mouthwash, or in a bottle of hand sanitizer does not justify restricting the sale of ethyl alcohol qua these items to minors. ${ }^{21}$ Historical properties are also relevant to legal status. For example, the fact that whisky (but not mouthwash or hand sanitizer) is designed to intoxicate supports the special legal status of whisky. These same points apply to sugar. As discussed in section (1), relational properties define the category of added sugar and explain this category's impact on obesity. It is thus no accident that every major health organisation recommends reductions specifically in the intake of this relationally defined category. Also, and recalling the corporate targeting of 'bliss points', added sugars are designed to 
deliver pleasurable sensations and - somewhat incredibly - they are often designed to increase appetite. ${ }^{22}$ They are generally not designed to promote nutritional goals or to satiate.

\section{An Argument Based on the Consequences of Implementing the Recommended Policy}

The previous section indicated how the recommended policy protects simultaneously two sets of rights: the child's right to an open future and parent's right to raise their child as they see fit. In this section I advance consequentialist considerations in support of this policy. I will claim that the policy is likely to promote the public good because it is uniquely well-suited to change the way that Americans think about added sugar.

By deterring the sale of sugary items to minors, the policy should have an immediate effect on one class of behaviors that causes and maintains obesity. This is similar to how laws restricting the sale of tobacco to minors - provided they are adequately enforced and there is merchant compliance - have led to significant changes in rates of youth smoking. ${ }^{23}$ Even granting this outcome, one might question whether the recommended policy can effectively address the obesity problem. The policy provides no legal deterrent for the parental supply of sugary items to minors, and it thus appears to neglect a central cause of childhood (and subsequent adult) obesity. In the remainder of this section I argue that the policy is in fact uniquely well-positioned to address this specific cause of obesity.

How can a policy that does not restrict adult preferences and behaviors nonetheless bring about significant changes to these preferences and behaviors? It can do so by transforming the social meaning of the activity to which those preferences and behaviors are directed. Social meanings - the complicated yet implicitly and commonly understood values and meanings attached to particular behaviors, artifacts, and institutions are powerful determinants of individual preferences and behavior. ${ }^{24}$ The management of social meaning can thus be critical to the success of public health campaigns. For instance, in the context of HIV prevention, Lessig describes how the social meaning of condom use will influence individual behavior and mediate public health outcomes. As Gostin et al. explain the point, "If bringing out a condom means "I think I (or you) might have a disease", it simply will not be done as frequently as it would be if the common meaning of the act is "Everybody uses condoms". ${ }^{25}$ According to Lessig, a central mechanism for transforming social meaning is semiotic 'tying'. Tying changes 'the social meaning of one act by tying it to, or associating it with, another social meaning . . . the tied text thereby gains some of the associated meaning of the tied-to text' ${ }^{26}$ Applying this idea to public health reform, one way to advance the goal of HIV prevention is to use educational campaigns or clever advertising that will tie condom use to something else (perhaps a celebrity or an image) that will confer to condom use the desired social meaning that 'everybody uses condoms'.

Curbing obesity on a large scale will require significantly transforming the social meaning of added sugar and its consumption; Americans will need to change the way that they think about sugar. Education and advertising have important roles to play here. ${ }^{27}$ But given the severity of the current obesity problem as well as the extent to which the current social meaning of added sugar (and soda and candy) is culturally entrenched, 
I do not think that these and similar measures (e.g. warning labels) are sufficient. The recommended policy, on the other hand, offers a tying mechanism that has unique potential to transform significantly the social meaning of added sugar and, when used in conjunction with education and other public health initiatives, address adequately the obesity problem.

First, note that there is historical precedent for the capacity of restrictive laws to transform the social meaning of risky behaviors and bring about long-term behavioral change. For example, due in large measure to the effect of mandatory seatbelt laws (e.g. the 'Click It or Ticket' campaign), seatbelt use for front-seat passenger vehicle occupants in the US has increased to 86 per cent in 2012 from 54 per cent in $1994 .{ }^{28}$ Importantly, this change is not simply the result of drivers' efforts to avoid legal penalties. While mandatory seatbelt laws were unpopular when first introduced, most drivers now endorse these laws and the value of seatbelts. The upshot is that seatbelt laws, in addition to their capacity to deter through penalty, have causally influenced motor vehicle occupant behavior by helping to transform the social meaning of seatbelt use. It is possible that when first introduced the recommended sugar policy will also not be universally popular. But similar to the career of seatbelt laws, added sugar restrictions can help transform the social meaning of a risky activity and thereby bring about long term changes in preferences and behavior. ${ }^{29}$

I now describe the tying mechanism through which the recommended policy can transform the social meaning of sugar and its consumption. Begin with the reasonable assumption that most people possess, at least tacitly, a schema for activities that are legally prohibited for minors. It is further reasonable to suppose that this schema encodes gambling, smoking, and drinking alcohol as prototypical members of the restricted class. Finally, it is reasonable to hold that this schema encodes these activities as harmful or at least risky - these activities can seriously affect long-term wellbeing and are not to be taken lightly. I am not claiming that the schema encodes that one should not pursue these activities. Rather, it encodes these activities as 'flagged' - as ones that might carry with them various costs that, at least for some, are significant enough that society has placed these activities in a special legal class. Note that individuals who possess this schema do not need to know how or why the minor restricted behaviors are risky - their inclusion by this schema in this class is sufficient to recommend prudence and influence practical reasoning. ${ }^{30}$

I submit that the recommended policy will tie the consumption of added sugar, soda, and candy to this schema and thereby transfer the social meaning of that schema to these sugar-related activities. Putting the point in simplest terms: consumers and parents will start tacitly to understand added sugar consumption less in terms of a neutral eating activity and more in terms of activities like smoking, drinking, or wagering at the craps table. Given the current social meaning of sugar, soda, and candy, this would mark a substantial conceptual shift. Returning to the target issue of this section, the most important aspect of this projected conceptual shift would concern how parents understand the activity of providing their children with items high in added sugar: they should increasingly understand this activity as more like providing electronic cigarettes or scratch-off lottery tickets to their children and less like providing sustenance to their children.

It is also worth noting that this projected shift in social meaning seems less likely to occur through purely epistemic channels like education. This is because these channels 
often require consumers to develop concepts and knowledge structures for sugar properties and obesity-related health concerns - concepts and knowledge structures that can be difficult to acquire and easy to ignore. The recommended policy's tying technique, on the other hand, does not depend on consumers developing new knowledge structures. It simply harnesses consumers' antecedent knowledge - knowledge encoded in a widely held schema for a familiar class of risky behaviors. In addition, the tied-to schema should not be easy to ignore. Depending on the scope and force of the recommended policy's implementation, one would not expect the triggering of this schema and its subsequent meaning transfer to be an uncommon occurrence.

If we accept the above conjectures, an attractive feature of the recommended policy is its capacity to change substantially adult purchasing and consuming behavior while not relying on coercive mechanisms that legally prohibit or penalise (e.g. tax) adult activities. Perhaps some will object that the prescribed intervention is still too paternalistic and that the state, through its attempt to circumvent reason-based behavioral change, has simply substituted manipulative meaning-management for legal statutes. Following Sunstein and Thaler, this general objection to nudging techniques and 'libertarian paternalism' might have more bite were it not the case that individuals enter into and currently live in a world that is already steeped in regulated social meanings. ${ }^{31}$ Moreover - and this is surely the case with respect to food and beverage - social meanings are constantly manipulated by corporate firms more interested in quarterly earnings than (and usually at the expense of) consumer wellbeing. Some degree of 'paternalistic' meaningmanagement thus seems inevitable and I contend that, considering the alternative sources of meaning-management, the recommended policy's projected effect on adult preferences - even if intended - is at most a mild affront to the interests of individual liberty.

\subsection{Possible Objections and Replies Concerning the Consequences of Implementing the Recommended Policy}

In this section I anticipate and respond to several objections that concern possible negative outcomes of implementing the recommended policy. Responding to these objections also provides further opportunity to discuss respects in which the rights-based arguments from Section 3 and the consequentialist considerations described above are unified.

One possible objection to the recommended policy is that it will promote the shaming and stigmatisation of obese bodies. In response, I emphasise two important points about the recommended policy. First, the policy does not construe obesity as an intrinsic harm. The primary harms that the policy seeks to address are those that stem from obesity-related health conditions, and as discussed in Section 3 much of the harm of those conditions consists in their capacity to close off opportunities that would otherwise be available to individuals. Second, the policy specifically targets children's dietary behavior - it does not restrict the dietary behavior of adults. These policy features contrast sharply with adult-directed coercive policies in ways that bear on the potential for shaming and stigmatisation. If coercive paternalistic policies implicitly or explicitly justify the forceful regulation of adult behavior on the basis of individual weakness of will, then one can reasonably claim that they construe obesity as resulting from weakness or irrationality and thus that the implementation of such 
policies would bolster negative social attitudes directed at obese bodies. In contrast, the recommended policy is not, and should not be perceived as being, staked on the assumption that obesity is intrinsically bad or that adult lifestyles that make obesity more probable cannot be rationally defended. Rather, the policy is premised on the less controversial and much less stigmatising assumption that the condition of obesity comes with various opportunity-restricting health risks — risks that only rationally autonomous adults are in the position to evaluate adequately and thereby accept.

It is more likely that the recommended policy could over time stigmatise parents who supply to their children excessive amounts of added sugar. However, in reference to the various empirical claims made in Sections 1 and 3 regarding the health consequences of children's excessive consumption of added sugar, I note that it is an open question to what extent such a stigma is unwelcome. ${ }^{32}$ If the policy did promote that stigma in a way that was not socially beneficial, it would be important to view that negative effect in the context of the policy's positive effects. For example, even if we judged the policy's projected positive outcomes as only somewhat likely, given that the policy offers a mechanism that has the potential to change the social meaning of sugar and thereby make a deep impact on a public health crisis, and because that mechanism does not infringe on parental rights or adult decision-making, I submit that the policy's high expected utility warrants its implementation. ${ }^{33}$

A second possible objection is that implementing the recommended policy will eliminate the purchasing of items high in added sugar as a source of decision making and thereby harm the development of a child's autonomy or practical reasoning skills. In reply, I note that it is not clear why the development of a person's decision-making abilities or individuality depends in any important way on having the opportunity in childhood to make decisions specifically about items very high in added sugar. That is, I see no grounds for holding that this domain of decision-making is any more central to or necessary for the cultivation of individuality and practical reasoning skill than are the decision-making domains of alcohol, gambling, tobacco, and military combat. Moreover, and recalling the discussion from Section 2, issuing identification cards to younger teenagers in the context of the recommended policy could in fact make available a unique and developmentally valuable domain of decision-making.

A possible counter to this reply repackages the original objection in terms of a policy cascade. This version of the objection states that the recommended policy establishes a regulatory precedent that would legitimise and facilitate the legal restriction of children's behavior in a variety of other domains. The total effect of these many restrictions, the objection continues, is the diminished opportunity for autonomy-training. In the conclusion, Section 5, I provide a brief discussion for why the recommended policy does not justify an over-reaching, domain-general restriction of children's behavior.

A third possible objection to the recommended policy is that it will diminish the intrinsic value - the joy, for example - of childhood. I offer two responses. First, even if there was a perceived loss of pleasurable experiences during childhood, this loss should be balanced with experiential gains that occur as a result of implementing the policy during later periods of one's lifetime. As discussed in Section 3, a policy that withholds specifically a child's freedom of choice in relation to items high in added sugar is a type of investment into that child's lifetime prospects. The long-term payoffs of that investment justify some degree of loss of childhood joy. Second, it is far from clear that the recommended policy would in fact compromise the experiential value of childhood. In 
fact, the opposite seems more likely: one's experience of childhood would be more valuable and pleasurable if — as made more likely by the implementation of the recommended policy - one is not conditioned on excessive amounts of added sugar, one does not experience drastic, sugar-caused 'highs' and 'lows', and one does not experience being overweight or obese.

\section{Conclusion}

The United States, like many other countries, is now in the grips of a severe obesity problem. One response to this problem involves the use of coercive mechanisms to restrict adult decision-making. Examples of this method include banning or taxing sugary items. This article developed an alternative response. I described a regulatory policy that would restrict the sale of items sufficiently high in added sugar to minors. I offered two central arguments for this policy. The first argument showed that the policy is required in order to protect simultaneously children's right to an open future and a parent's right to parental control. The second argument claimed that the policy is likely to promote the public good because the policy is uniquely well-suited to change the way that Americans think about sugar and, as a result, their purchasing and consuming behavior.

Together, these arguments also suggest a limit for the legal restriction of a minor's freedom of choice. I suggest that if a similar set of arguments cannot be made for other domains of children's activity, then this is a compelling reason for not legally restricting children's freedom of choice in those domains. Specifically, with respect to the restriction of a type of children's activity, the preceding account makes salient three questions. First, is the activity very harmful such that it is likely to close off important future opportunities for the adults who these children will become? Second, is the restriction of the activity consistent with the protection of parental rights? Third, are there reasonable grounds to maintain that the restriction of the activity will promote the general public good? When the answers to all three questions are 'yes', then I suggest that there are compelling reasons to restrict this type of children's activity. When the answers to one or several of these questions is 'no', then there are compelling reasons not to restrict the activity. I would not be surprised if this schema, employed in a structurally similar way to its employment in this article, offered compelling grounds for restricting children's purchasing of items very high in trans fats. On the other hand, I am confident that the schema would not offer compelling grounds for restricting children's skateboard riding, and I would be surprised if it offered compelling grounds for restricting children's purchasing of items high in saturated fat. Of course, adequate analyses of these cases will require careful evaluations of the value, harm, and empirical evidence surrounding the target activities. While such analyses are beyond the scope of this article I hope that the article can provide an effective framework for their development and assessment.

If successful, this article motivates a serious discussion of how best to further develop and implement the recommended policy. This will include deliberation over unspecified components of the policy (e.g. age and caloric percentage) and also administrative scale (e.g. city, state, and/or federal levels of implementation). While these discussions are likely to generate unique challenges for the recommended policy, it will be important to evaluate whether these challenges reflect the interests of consumers or the interests of 
for-profit companies. More generally, the article's arguments function to exert dialectical pressure on defenders of the status quo. I am particularly interested in whether defenders of the status quo can offer a compelling moral justification for current laws that permit the sale of items very high in added sugar to minors. Granting that such a justification should not be premised on the financial interests of corporations that profit from the sale of added sugar, I am less than optimistic that such a justification is forthcoming. ${ }^{34}$

\section{Theodore Bach, Department of Philosophy, Bowling Green State University, 1 University Drive, Huron, OH 44839, USA. theodorebach@gmail.com}

\section{NOTES}

1 See, for example, Cynthia L. Ogden et al., 'Prevalence of obesity and trends in body mass index among US children and adolescents, 1999-2010', Fournal of the American Medical Association 307,5 (2012): 483-490, which classifies children as obese if they have 'a body mass index (BMI; calculated as weight in kilograms divided by height in meters squared) greater than or equal to the 95th percentile on the BMI-for-age growth charts ...' (p. 483). Children are classified as overweight if their BMI percentile range is between 85 and 95. Percentiles for the BMI-for-age growth charts correlate with body-fat percentile ranges that are known to impact and predict health status.

2 See Megan M. Kelsey et al., 'Age-related consequences of childhood obesity', Gerontology 60,3 (2014): 222-228; Ogden et al. op. cit.; and Centers for Disease Control and Prevention (CDC) 'Vital signs: Obesity among low-income, preschool-aged children - United States, 2008-2011', MMWR. Morbidity and Mortality Weekly Report 62,31 (2013): 629-634. It is noteworthy that these percentages are even higher for Hispanic and black children.

3 Centers for Disease Control and Prevention (CDC), 'Vital signs: Progress on childhood obesity', August (2013) http://www.cdc.gov/VitalSigns/ChildhoodObesity/?s_cid=bb-dnpao-obweb-103.

4 Eric A. Finkelstein et al., 'Annual medical spending attributable to obesity: payer-and service-specific estimates', Health Affairs 28,5 (2009): w822-w831.

5 See Vasanti S. Malik et al., 'Sugar-sweetened beverages and weight gain in children and adults: A systematic review and meta-analysis', The American fournal of Clinical Nutrition 98,4 (2013): 1084-1102; and Vasanti S. Malik, Matthias B. Schulze \& Frank B. Hu, 'Intake of sugar-sweetened beverages and weight gain: A systematic review', The American fournal of Clinical Nutrition 84,2 (2006): 274-288.

6 N.Y. Sup. Ct., 'New York Statewide Coalition of Hispanic Chambers of Commerce v. New York City Dept. of Health and Mental Hygiene’, No. 653584/12. N.Y. Sup. Ct. N.Y. Cty., 11 March (2013), p. 34.

7 See NCSL. Indoor Tanning Restrictions for Minors - A State-by-State Comparison [website]. Washington DC and Denver CO: National Conference of State Legislatures (updated Jan 2015). Available: http:// www.ncsl.org/research/health/indoor-tanning-restrictions.aspx

8 Joel Feinberg, 'A child's right to an open future', in W. Aiken \& H. LaFollette (eds) Whose Child? Children's Rights, Parental Authority and State Power (Totowa, NJ: Littlefield, Adams, 1980), pp. 124-153, at p. 127.

9 Ibid., p. 127.

10 Although, there are reasons to think that nicotine use in adolescents can affect brain development. There is also a forthcoming study in the journal Nicotine and Tobacco Research that reports that some e-cigarettes produce carcinogens.

11 Solveig A. Cunningham, Michael R. Kramer \& KM Venkat Narayan, 'Incidence of childhood obesity in the United States', New England Fournal of Medicine 370,5 (2014): 403-411.

12 Penny Gordon-Larsen et al., 'Five-year obesity incidence in the transition period between adolescence and adulthood: The National Longitudinal Study of Adolescent Health', The American fournal of Clinical Nutrition 80,3 (2004): 569-575, at p. 573.

13 Kelsey et al. op. cit.

14 This last point is contentious. For discussion see Ashley N. Gearhardt et al., 'Can food be addictive? Public health and policy implications', Addiction 106,7 (2011): 1208-1212; J.R. Ifland et al., 'Refined food addiction: A classic substance use disorder', Medical Hypotheses 72,5 (2009): 518-526; and Hisham, I. Ziauddeen, Sadaf Farooqi \& Paul C. Fletcher, 'Obesity and the brain: How convincing is the addiction model?', Nature Reviews Neuroscience 13,4 (2012): 279-286. 
15 See, e.g., Norman Daniels, Am I My Parents'Keeper?: An Essay on fustice Between the Young and the Old (New York: Oxford University Press, 1998), p. 70: 'Impairment of normal functioning through disease and disability restricts individuals' opportunities relative to that portion of the normal range their skills and talents would have made available to them were they healthy. If individuals' fair shares of the normal range are arrays of life plans they may reasonably choose, given their talents and skills, then disease and disability shrinks their shares from what is fair'.

16 See Camille Schwartz, Sylvie Issanchou \& Sophie Nicklaus, 'Developmental changes in the acceptance of the five basic tastes in the first year of life', British fournal of Nutrition 102,9 (2009): 1375-1385. In this respect, the case for restricting children's access to added sugar goes beyond the analogy to tobacco and alcohol - products that rely on an acquired taste rather than an innate preference.

17 See Michael Moss, Salt, Sugar, Fat: How the Giants Hooked Us (New York: Random House, 2013).

18 For example, a child's condition of being obese would not be sufficient grounds for intervention. To justify intervention it would be at least necessary to establish that the child's excessive consumption of parent-supplied added sugar was a central cause of the child's condition of being obese. There is legal precedent for such interventions. For example, in 2011 Ohio social workers arranged for an eight-year-old obese child to be removed from his home in Cleveland Heights. The state argued that the parent's failure to address adequately the child's obesity was a form of medical neglect — see Rachel Dissell, 'County places obese Cleveland Heights child in foster care', The Plain Dealer 26 November (2011).

19 Peter Singer, 'Famine, affluence, and morality', Philosophy and Public Affairs, 1,1 (1972): 229-243.

20 See, e.g., Lee Strunin et al., 'Familial drinking in Italy: Harmful or protective factors?', Addiction Research $\mathcal{E}$ Theory 18,3 (2010): 344-358; and Fiorenzo Laghi et al., 'The role of parenting styles and alcohol expectancies in teen binge drinking: A preliminary investigation among Italian adolescents and their parents', Drugs: Education, Prevention and Policy 20,2 (2013): 131-139.

21 Moreover, many industrial and familiar household products contain 'denatured' ethyl alcohol, which is ethyl alcohol with small amounts of other chemicals added to make it unpalatable.

22 See Moss op. cit.

23 For example, in a national study of the relationship between vendor compliance to laws prohibiting the sale of tobacco to minors and adolescent smoking, DiFranza and colleagues found that daily smoking for adolescents dropped $2 \%$ for every $1 \%$ increase in vendor compliance. See Joseph R. DiFranza, Judith A. Savageau \& Kenneth E. Fletcher, 'Enforcement of underage sales laws as a predictor of daily smoking among adolescents: A national study', BMC Public Health 9,1 (2009): 107.

24 See Lawrence Lessig, 'The regulation of social meaning', The University of Chicago Law Review (1995): 943-1045, for a fuller discussion of the definition of social meaning. Lessig claims that social meanings are 'the semiotic content attached to various actions, or inactions, or statuses, within a particular context', and that 'their force in part hangs upon their resting upon a certain uncontested, or taken-for-granted, background of thought or expectation - alternatively, that though constructed, their force depends upon them not seeming constructed' (p. 951). For a more analytically precise discussion of how distinctions, institutions, and objects are 'socially constructed' and yet have causal force, see especially Sally A. Haslanger, Resisting Reality: Social Construction and Social Critique (Oxford: Oxford University Press, 2012). Drawing on Ian Hacking's research, Haslanger also makes clear how the social and causal force of a category can depend, as Lessig puts it, upon it 'not seeming constructed'.

25 Lawrence O. Gostin, Scott Burris \& Zita Lazzarini, 'The law and the public's health: A study of infectious disease law in the United States', Columbia Law Review (1999): 59-128, at p. 73.

26 Lessig op. cit., p. 1009.

27 For example, Cynthia L. Ogden et al., 'Prevalence of childhood and adult obesity in the United States, 2011-2012', FAMA The fournal of the American Medical Association 311,8 (2014): 806-814, report some recent improvements in the obesity rates of two- to five-year-olds, and if these improvements are both meaningful and lasting then it is tempting to credit education and advertising. However, a follow-up study by Asheley Cockrell Skinner \& Joseph A. Skelton, 'Prevalence and trends in obesity and severe obesity among children in the United States, 1999-2012', $\mathcal{F A M A}$ Pediatrics 168,6 (2014): 561-566, which used the same data source as Ogden et al. (op. cit., 2014) but examined a longer period of time, indicates that obesity rates for this age group have not improved. This finding is consistent with the argument below that reversing the obesity problem will require additional and stronger policy measures.

28 David G. Kidd, Anne T. McCartt \& Nathan J. Oesch, 'Attitudes toward seat belt use and in-vehicle technologies for encouraging belt use', Traffic Injury Prevention 15,1 (2014): 10-17. 
29 Because the restrictions imposed by seatbelt laws did not require a radical departure from existing cultural norms, they were able to gain a foothold within and eventually transform those norms. As discussed in Section 3.1., similar considerations with respect to sugar consumption recommend restricting children's sugar-related activities rather than adult's activities. Arguably, only the former type of restriction can gain a foothold within and eventually transform the current social meanings of sugar consumption, dietary behavior, and parenting.

30 I have in mind here something similar to Putnam's division of linguistic labor - see Hilary Putnam, 'Meaning and reference', The fournal of Philosophy 70,19 (1973): 699-711.

31 See Cass R. Sunstein \& Richard H. Thaler, 'Libertarian paternalism is not an oxymoron', The University of Chicago Law Review (2003): 1159-1202.

32 The general issue of stigma as it relates to public health policy - particularly when that issue is considered in the context of the social meaning of food and also the historical basis of social kinds (see Theodore Bach, 'Gender is a natural kind with a historical essence', Ethics 122,2 (2012): 231-272) — is a complicated one. Any adequate discussion of that issue is beyond the scope of this article.

33 Moreover, while I have focused on how the reduction of obesity-related health conditions can protect the availability of individual opportunity, such a reduction would also reduce the approximately 150 billion dollars in medical expenses that is attributable annually to obesity in the United States.

34 I am grateful to Colleen Murphy, Pat Fleming, David Slutsky, and audience members at the 2015 Central Divisional Meeting of the American Philosophical Association for providing helpful comments on an earlier version of this article. I am also grateful to two anonymous reviewers and an Editor from the fournal of Applied Philosophy for providing helpful feedback. In addition, I wish to thank the following friends and family members for providing challenging conversations that helped me sharpen my thinking on these matters: Joe Wagner, Stephanie Walls, Karl Tupper, Jamie Rapavy, Jolie Rapavy, Gerald Bach, Darrin Bach, and Maureen Bach. 